\title{
Assessment of syphilis infection among pregnant women and its associated risk factors at Sovu health center in Rwanda
}

\author{
Augustin Nshimiyimana, Joseph Mucumbitsi, Callixte Yadufashije and Francois N. \\ Niyonzima*
}

\begin{abstract}
Department of Biomedical Laboratory Sciences, Faculty of Applied Fundamental Sciences, INES-Ruhengeri, Rwanda.
\end{abstract}

Emails: augunshimiye@gmail.com; jephmicro@gmail.com; cyadufashije@ines.ac.rw; niyofra@yahoo.com

*Corresponding author: Dr Niyonzima N. Francois, Email: niyofra@yahoo.com.

\begin{abstract}
Syphilis in pregnant women caused by Treponema pallidum remains a major cause of reproductive morbidity and poor pregnancy outcomes in developing countries. Severe neonatal infections, stillbirths, perinatal deaths, and low birth weight babies are common among mothers with syphilis infection. The aim of the study was to assess the prevalence and risk factors associated to syphilis in pregnant women. A cross-sectional and retrospective studies were conducted among pregnant women who attended the prenatal service at the Gisovu health center. Participants were pregnant women who tested positive for syphilis based on lab results and responses collected from anonymous questionnaires completed with sexual behaviors, demographics, sexual partners, history of abortion, and knowledge about STDs. The prevalence of syphilis was 5.74\%. Syphilis was associated to the history of previous abortion $(P=0.005<0.05)$, a low level of education $(P=0.049<0.05)$, and marital status $(P=0.044<0.05)$. The main associated behavioral factor was women who had sex with different partners using condom and did not acquire syphilis infection $(P=0.00<0.05)$. Syphilis is still a public health concern in patients and especially in pregnant women as shown by the findings of this study. It is very important to screen all pregnant women for syphilis and to strengthen the existing antenatal care services and health education on transmission and prevention of the disease.
\end{abstract}

Keywords: prevalence, syphilis, pregnant women, risk factors, serological tests

\section{INTRODUCTION}

Despite the availability of efficient technologies for diagnosis and treatment, syphilis, a sexually transmitted disease, persists in the $21^{\text {st }}$ century as a worldwide public health problem. It affects two million pregnant women a year and causes a negative impact on the health of women and their babies [1]. Gestational syphilis is a public health problem in the world. It is estimated that approximately two million pregnant women present active infection each year and less than $10 \%$ are diagnosed and treated [2]. Approximately $90 \%$ of the cases occur in developing countries; however, a resurgence can be observed in developed nations $[3,4]$.

The prevalence of syphilis infection among pregnant women in sub-Saharan Africa is estimated at $2.7 \%$, which represents nearly one million high-risk pregnancies each year [5]. In the United States, recent data show that more than 30,000 cases of primary and secondary syphilis infection have been reported [6]. The disease causes multiple adverse outcomes in pregnancy, with an estimated 4.5 times higher risk when compared to pregnant women without the diagnosis $[7,8]$. As it causes vertical transmission, it can cause miscarriage, premature delivery, and fetal and neonatal death if not treated properly. New borns of mothers with syphilis who are untreated or inadequately treated may be asymptomatic. This can lead to the absence of diagnosis and treatment, causing serious damage to their health, with psychological and social repercussions [9].

The disease control recommendations strengthen interventions aimed at prevention and early diagnosis, paying attention to the most exposed population groups [10]. Many conditions have been linked with the occurrence of syphilis during pregnancy, including socio-demographic, behavioral and health factors [11]. Syphilis is spread through sexual or mother-to-child contact during pregnancy or childbirth [8]. During pregnancy, infection with syphilis may also enlarge the risk of mother-to-child transmission of HIV in cases where mothers are co-infected [12]. Syphilis during pregnancy, which is not properly treated, has been reported to cause poor pregnancy results in about half of cases - stillbirths in 40\%, neonatal death and morbidity in $20 \%$ and low birth weight deliveries in the early stages in $20 \%$ [13-14].

Among the socio-demographic factors, low level of education, low income and marital status (common-law or cohabitation) are identified as risky situations and an 
expression that syphilis is linked, but not limited to poverty.

Equally important are the behaviors that make women vulnerable, which are associated with a higher risk, such as lower age of first sex and pregnancy, high number of sexual partners, non-observance of safer sex practices, use of illicit and psychoactive drugs, among others $[8,10$, 15]. Some of these conditions increase the risk when linked to poverty, poor health education and access to health services. However, despite a large proportion of pregnant women with access to antenatal care, very little about the quality of care they receive is still known. The aim of this paper was to assess the prevalence and risk factors associated to syphilis in pregnant women at Sovu health center.

\section{METHODS}

\section{Study design and area}

A health center-based cross-sectional study was conducted among pregnant women attending the antenatal care unit of Sovu health center. Pregnant women who attended the health center during the sample collection period (September to December 2019) were considered as the chosen target group. Sovu health center is one of Kabaya hospital health centers. It is located in Sovu sector, Ngororero District, in Western province of Rwanda

\section{Ethical consideration and study participants}

Permission to conduct the research was granted by Sovu health center and INES Ruhengeri ethic committees. Patients were informed about the study and its benefits. Patients who were considered and who voluntarily accepted to participate were enrolled in the study. The right to privacy and confidentiality were respected. The collected specimens were assigned anonymous codes and the data generated were only used for study purposes. Following acquisition of informed consent, a total of 174 participants were included in this study. Out of them, 13 participants were diagnosed as positive for syphilis infection by the routinely used technique (ECOTEST-RPR) at Sovu health center. Then treatment records of all patients were reviewed to initiate specific treatment.

\section{Specimen collection and processing}

A blood sample was taken from each participant and centrifuged to obtain the serum. The obtained sera were kept in cold place at $-10{ }^{\circ} \mathrm{C}$ while waiting the laboratory tests to be performed. Before running the rapid plasma reagain (RPR), the preserved serum specimens were defrosted at $37{ }^{\circ} \mathrm{C}$ in a water bath to get ice and completely dissolved. Subsequently, RPR and Treponema pallidum hemagglutination antigen (TPHA) were carried out and the results were interpreted according to the kit manufacturer's instructions. A sample that showed an equivocal result for the test was retested.

\section{Data analysis}

Questionnaire and serodiagnosis data were analysed using SPSS version 2020. Chi square $(\chi 2)$ test was conducted to determine the relationship between syphilis and risk factors. $<0.05$ probability was considered as significant.

\section{RESULTS}

Socio-demographic characteristics of pregnant women attending Sovu health centre

The age range of subjects were $\leq 18-46$ years old. The majority of participants were in the age of 26 to 32 years old. The highest number of the participants was that of married with $78 \%$. Most of them (45\%) were able to reach primary school and (51\%) belonged to casual labours (Table 1).

TABLE 1: Social demographic characteristics of pregnant women attending Sovu health centre from September 2019 to December 2019

\begin{tabular}{lcc}
\hline Characteristics & Frequency (n) & Percentage (\%) \\
\hline Age categories (years) & 7 & 4.02 \\
$\leq 18$ & 37 & 21.26 \\
$19-25$ & 72 & 41.37 \\
$26-32$ & 49 & 28.16 \\
$33-39$ & 9 & 5.17 \\
$40-46$ & & 19.54 \\
Matrimonial status & 34 & 78.16 \\
Single & 136 & 2.29 \\
Married & 4 & 85.1 \\
Divorced & & 14.9 \\
Residential areas & 148 & \\
Sovu sector & 26 & 17.24 \\
Surrounding areas & & 45.40 \\
Educational level & 30 & 29.88 \\
Non formal education & 79 & 7.47 \\
Primary education & 52 & \\
High school education & 13 & 29.31 \\
University education & & 51.14 \\
Occupational place & 51 & 17.24 \\
Unwaged & 89 & 2.29 \\
Casual labours & 30 & \\
Privates & 4 & \\
Government & & \\
\hline
\end{tabular}


Socio-demographic features of pregnant women in relation to the serostatus analysis at Sovu health centre from September 2019 to December 2019

The overall prevalence of syphilis was 10/174(5.74\%). All syphilis seropositive cases were observed among single, married and divorced pregnant women who were house wives and casual labours by occupation. In terms of age, high syphilis seroprevalence was observed among women in the age group of 19-25 (3.44\%). Sociodemographic features of pregnant women in relation to the serostatus analysis at Sovu health centre are shown in the table 2 .

TABLE 2: Socio-demographic features of pregnant women in relation to the serostatus analysis at Sovu health centre from September 2019 to December 2019

\begin{tabular}{|c|c|c|c|c|c|}
\hline \multirow{2}{*}{ Characteristics } & \multirow{2}{*}{$\begin{array}{l}\text { Tested } \\
\text { cases }\end{array}$} & \multicolumn{2}{|c|}{$\begin{array}{c}\text { Serology results of } \\
\text { T. pallidum with RPR and TPHA }\end{array}$} & \multirow[t]{2}{*}{$\chi^{2}(\mathrm{df})$} & \multirow[t]{2}{*}{$P$ (value) } \\
\hline & & Positive & Negative & & \\
\hline \multicolumn{6}{|l|}{$\begin{array}{l}\text { Age categories } \\
\text { (years) }\end{array}$} \\
\hline$\leq 18$ & 7 & $0(0.4)$ & $7(6.6)$ & \multirow{5}{*}{$2.678(4)$} & \multirow{5}{*}{0.613} \\
\hline $19-25$ & 37 & $1(2.1)$ & $36(34.9)$ & & \\
\hline $26-32$ & 72 & $6(4.1)$ & $66(67.9)$ & & \\
\hline $33-39$ & 49 & $2(2.8)$ & $47(46.2)$ & & \\
\hline $40-46$ & 9 & $1(0.5)$ & $8(8.5)$ & & \\
\hline \multicolumn{6}{|l|}{ Matrimonial status } \\
\hline Single & 34 & $3(2)$ & $31(32)$ & \multirow{3}{*}{$6.238(2)$} & \multirow{3}{*}{0.044} \\
\hline Married & 136 & $6(7.8)$ & $130(128.2)$ & & \\
\hline Divorced & 4 & $1(0.2)$ & $3(3.8)$ & & \\
\hline \multicolumn{6}{|l|}{ Residential areas } \\
\hline Sovu sector & 148 & $9(8.5)$ & $139(139.5)$ & \multirow{2}{*}{$0.204(1)$} & \multirow{2}{*}{0.652} \\
\hline Surrounding areas & 26 & $1(1.5)$ & $25(24.5)$ & & \\
\hline \multicolumn{6}{|l|}{ Educational level } \\
\hline Non formal education & 70 & $6(4)$ & $64(66)$ & \multirow{4}{*}{$7.845(3)$} & \multirow{4}{*}{0.049} \\
\hline Primary education & 56 & $3(3.2)$ & $53(52.8)$ & & \\
\hline High school education & 43 & $1(2.5)$ & $42(40.5)$ & & \\
\hline University education & 5 & $0(0.3)$ & $5(4.7)$ & & \\
\hline \multicolumn{6}{|l|}{ Occupational place } \\
\hline Unwaged & 51 & $5(2.9)$ & $46(48.1)$ & & \multirow{4}{*}{0.429} \\
\hline Casual labours & 89 & $3(5.1)$ & $86(83.9)$ & \multirow{3}{*}{$2.768(3)$} & \\
\hline Privates & 30 & $2(1.7)$ & $28(28.3)$ & & \\
\hline Government & 4 & $0(0)$ & $4(3.8)$ & & \\
\hline
\end{tabular}

Infection with syphilis in relation to clinical history, sexual habits and recognition of the disease in pregnant women.

In this study, the infection with syphilis in relation to clinical history, sexual habits and recognition of the disease was assessed. Table 3 showed that the majority of positive cases were with or without history of previous abortion, with 4 and $1.72 \%$ of participants, respectively. A big number of participants with or without knowledge of preventive measures via condom use was 3.44 and $2.28 \%$, respectively.

\section{DISCUSSION}

In the present study, the prevalence and risk factors associated to syphilis in pregnant women at Sovu health center were investigated. A total of 174 pregnant women were registered in the study. All women approached for participation were consented, interrogated and donated clinical specimens (contribution rate $=100 \%$ ). The general prevalence $(5.74 \%)$ of syphilis identified in this study demonstrated a lower rate than that obtained in a study conducted in Brazilian areas. This study revealed a rate of $13.9 \%$, with high prevalence in Rio de Janeiro (23.5\%) and Belo Horizonte (13.9\%) [16]. The seroprevalence of syphilis among pregnant women in the current study was $5.74 \%$. This disagrees with reports from two hospital studies in Ethiopia [17, 18]. However, it is much higher than the seropositivity for syphilis reported among pregnant women in Nigeria (0.3\%) [19] and Tanzania $(0.5 \%)$ [20]. It is also higher than the results for India $(0.36 \%)$ [21] and China $(0.39 \%)$ [22]. It is also higher than the prevalence of 4.3, 5.0 and lower at 5.8 and $7.3 \%$ reported respectively, in Botswana [20], Malawi [23], in the delta of Niger, Nigeria [24] and Tanzania [25].

A study conducted in the São Paulo (Brazil) homeless population, which evaluated the prevalence of syphilis and associated factors using rapid testing in 1,405 individuals, revealed a prevalence of $7 \%$ [26]. Another study carried out in Angola, Africa among individuals attending a center of reference and testing for HIV showed higher positivity for syphilis (15\%) among the 431 research subjects [27]. These variations in syphilis seroprevalence among different individuals within and outside Rwanda may reflect variations in sexual practices and community behavior, syphilis awareness and differences in access to treatment for STDs, cultural practices, as well as differences in laboratory techniques used to detect T. pallidum infection.

Another relevant issue highlighted in this study is that a low level of education can interfere with the understanding of guidelines for prevention methods. This highlights the findings of research carried out in São Paulo and Recife, where the less educated had erroneous information on the forms of prevention and contagion, reflected by a higher prevalence of STDs in this group [28]. 
TABLE 3: Infection with syphilis in relation to clinical history, sexual habits and recognition of the disease in pregnant women

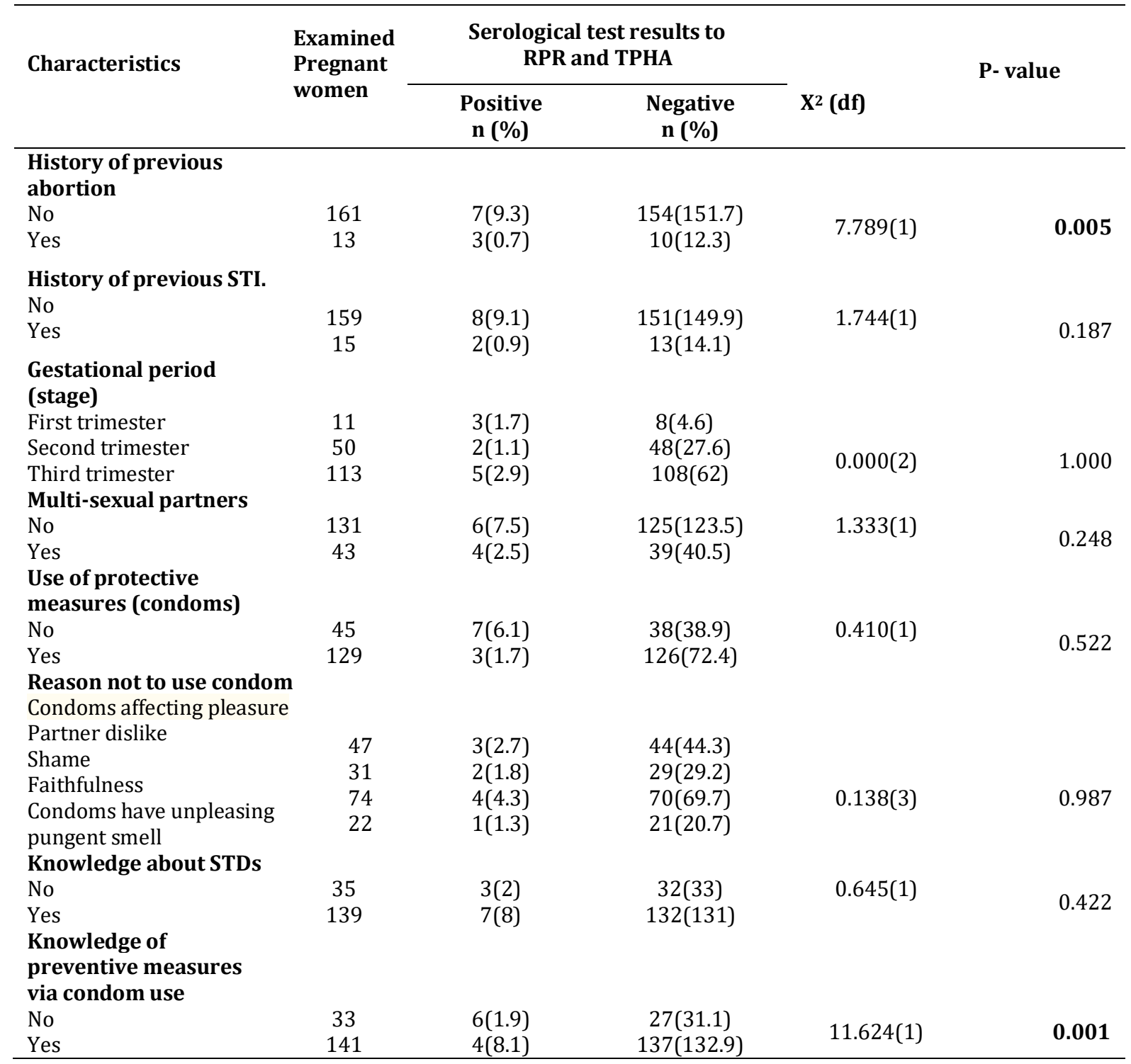

It is understood that some issues of an educational nature may interfere with the adoption of prevention methods. For instance, a low level of education may be involved to the increase of syphilis infection.

The marital status analysis highlights the results of a study conducted in Cuba of 120 individuals who tested positive for syphilis, in which $76.7 \%$ did not have stable relationships. It is believed that subjects who do not have a fixed association tend to engage more partners and thus increase the possibility of getting STDs [29]. Studies show that a history of STDs is associated with syphilis, especially in pregnant women. They demonstrated high rates of STDs. In sex workers, the prevalence of STDs was $71.6 \%$ [28]. Dissimilar results were found in this study with $8.6 \%$ of females with STDs.

The present statistical results showed that pregnant women who were positive for syphilis had a history of experiencing abortion and it was found to be associated with syphilis in this study with significance level $(P=$ $0.005<0.05$ ). This result is in agreement with a number of previous studies which reported unfavourable pregnancy outcomes in more than half of pregnant women with untreated syphilis [30-31]. In a similar study, abortion was found to be associated with syphilis. The association can be explained by the fact that an undesired pregnancy is normally the consequence of risky sexual habits, which generates a double risk of pregnancy and exposure to STIs. This has also been approved by previous studies in which high rates of STIs were observed in women seeking an induced abortion at family planning clinics [32] and in patients referred for termination of pregnancy [33]. Generally, this study showed that participants had knowledge of condom use to prevent transmission of STDs when used regularly with significant association of $(P=0.001<0.05)$. Similar results were reported [34].

\section{CONLUSION}

The study aimed to identify the prevalence of syphilis and associated risk factors in pregnant women who have been tested for syphilis infection. Many demographic and behavioural risk factors have been found to be associated with syphilis among pregnant women in the study area. There is still the problem of syphilis in pregnant women as shown by the results. It is more important to screen all pregnant women for syphilis infection during the antenatal care. Therefore, it is much better to strengthen the existing antenatal services and 
health education on the mode of transmission and preventive measures of syphilis infection.

\section{ACKNOWLEDGEMENTS}

INES Ruhengeri and Savu health center are acknowledged for the present work.

\section{REFERENCES}

[1] World Health Organization. Worldwide elimination of congenital syphilis: Rationale and strategy for action. Geneva: WHO; 2008.

[2] Arnesen, L., Martinez, G., Mainero, L., Serruya, S., Durán, P. (2015). Gestational syphilis and stillbirth in Latin America and the Caribbean. Int J Gynaecol Obstet. 128 (3), 241-5.

[3] Braccio, S., Sharland, M., \& Ladhani, S. N. (2016). Prevention and treatment of mother-to-child transmission of syphilis. Curr Opin Inf Dis, 29 (3), 268-274.

[4] Cameron, C. E., Lukehart, S. A. (2014). Current status of syphilis vaccine development: need, challenges, prospects. Vaccine, 32(14), 1602-1609.

[5] WHO. (2013). Baseline report on global sexually transmitted infection surveillance 2012. Tech. Rep., 2013.

[6] Domingues, R. M. S. M., Saracen, V., Hartz, Z. M. D. A. and Leal, M. D. (2013). Congenital syphilis: sentinel event on the quality of prenatal care. Revista de Saúde Pública, 47(1), 147-157.

[7] World Health Organization (2001). Global prevalence and incidence of selected curable sexually transmitted infections: overview and estimates. Tech. Rep., World Health Organization, Geneva, Switzerland.

[8] Gomez, G. B., Kamb M. L., Newman, L. M., Mark, J., Broutet, N., Hawkes, S. J. (2013). Untreated maternal syphilis and adverse outcomes of pregnancy: a systematic review and meta-analysis. Bull WHO, 91(3), 217-226.

[9] Casal, C.A.D., Silva, M.O., Costa, I.B., Araújo, E.C., Corvelo, T.C.O. (2011). Molecular detection of Treponema pallidum sp. Pallidum in blood samples of VDRL- seroreactive women with lethal pregnancy outcomes: a retrospective observational study in northern Brazil. Rev Soc Bras Med Trop, 44(4), 451-6.

[10] Domingues, R.M.S.M., Szwarcwald C.L., Souza Junior, P.R.B., Leal, M.C. (2014). Prevalence of syphilis in pregnancy and prenatal syphilis testing in Brazil: Birth in Brazil study. Rev Saude Publica, 48(5), 76674.

[11] Lago, E.G., Rodrigues, L.C., Fiori, R.M., Stein, A.T. (2004). Congenital syphilis: identification of two distinct profiles of maternal characteristics associated with risk. Sex Transm Dis, 31(1), 33-7.

[12] Fleming, D. T., and Wasserheit, J. N. (1999). From epidemiological synergy to public health policy and practice: the contribution of other sexually transmitted diseases to sexual transmission of HIV infection. Sexually Transmitted Infections, 75 (1), 317.

[13] Hawkes, S. J., Gomez, G. B., Broutet, N. (2013). Early antenatal care: does it make a difference to outcomes of pregnancy associated with syphilis? a systematic review and meta-analysis. PLOS ONE, 8(2), e56713.
[14] Mullick, S., Watson-Jones, D., Beksinska, M., Mabey, D. (2005). Sexually transmitted infections in pregnancy: prevalence, impact on pregnancy outcomes, and approach to treatment in developing countries, Sexually Transmitted Infections, 81(4), 294-302.

[15] Melo, N.G.D.O., Melo Filho, D.A., Ferreira, L.O.C. (2011). Intra-urban differentials of congenital syphilis in Recife, Pernambuco, Brazil (2004-2006). Epidemiol Serv Saude, 20(2), 213-22.

[16] Guimarães, M.D.C, Ceccato, M.G.B, Gomes, R.R.F.M, Rocha, G.M, Camel, L.V, Carmo R.A, et al. Vulnerabilidade e fatores associados a HIV e sífilis em homens que fazem sexo com homens. Rev Méd Minas Gerais. 2013;23(4):412-26

[17] Ethiopian Health and Nutrition Research Institute. Report on the 2009 round antenatal care sentinel HIV surveillance in Ethiopia: AddisAbaba; 2011.

[18] Mulu, A., Kassu, A., Tessema, B., Yismaw, G., Tiruneh, M., Moges, F. et al. Sero-prevalence of syphilis and HIV-1 during pregnancy in a teaching hospital in northwest Ethiopia. Jpn J Infect Dis. 2007; 60:193-5.

[19] Kuznik, A., Lamorde, M., Nyabigambo, A., Manabe, Y.C. (2013). Antenatal syphilis screening using point-of-care testing in sub-Saharan African countries: a cost-effectiveness analysis. PLoS Med. 10 (11): e1001545.

[20] Eticha, B.T., Sisay, Z., Alemayehu, A., Shimelis, T. (2013). Seroprevalence of syphilis among HIVinfected individuals in Addis Ababa, Ethiopia: a hospital-based cross-sectional study. BMJ Open. 3: e002293.

[21] Tessema, B, Yismaw G., Kassu, A., Amsalu, A., Mulu, A., Emmrich F., et al. (2010). Sero-prevalence of HIV, HBV, HCV and syphilis infections among blood donors at Gondar University teaching hospital, northwest Ethiopia: declining trends over a period of five years. BMC Infect Dis. 10:111.9.

[22] Zenebe, Y., Mulu W., Yimer, M., Abera B. (2014). Sero-prevalence and risk factors of hepatitis B virus and human immunodeficiency virus infection among pregnant women in Bahir Dar city, northwest Ethiopia: a cross sectional study. $B M C$ Infect Dis. 14:118.

[23] Bukor, M., Audu B.M., Takoivi, A., joy, B.B., killimo, A. (2009). Is routine antenatal screening for syphilis in Nigeria still justified clinically and economically? Saudi Med J. 30 (10):1311-5.

[24] Yang, L.G., Tucker, J.D., Liu, F.Y., Ren, X.Q., Hong, X, Wang, C., et al. (2013). Syphilis screening among 27,150 pregnant women in south Chinese rural areas using point-of-care tests. PLoS One. 8 (8):e72149.

[25] Azeze, B., Fantahun, M., Gebre, Kidan, K., Haile, T. (1995). Seroprevalence of syphilis amongst pregnant women attending antenatal clinics in a rural hospital in North West Ethiopia. Genitourin Med. 71:347-50.

[26] Pinto, V.M., Tancredi, M.V., Ramos, de Alencar, H.D., Camolesi, E, Holcman, M.M., Grecco, J.P., et al. (2014). Prevalência de Sífilis e fatores associados a população em situação de rua de São Paulo, Brasil, 
com utilização de Teste Rápido. Rev Bras Epidemiol. 17(2):341-54.

[27] Guimarães, Nebenzahl, H., Lopes, A., Castro, R., Pereira, F. (2013). Prevalence of human immunodeficiency virus, hepatitis $C$ virus, hepatitis $B$ virus and syphilis among individuals attending anonymous testing for HIV in Luanda, Angola. $S$ Afr Med J. 103(3):186-8.

[28] Garcia, S., Souza, F.M. (2010) Vulnerabilidades ao HIV/aids no Contexto Brasileiro: iniquidades de gênero, raça e geração. Saude Soc. 19 (supl 2):9-20.

[29] Miranda AE, Rosetti Filho E, Trindade CR, Gouvêa GM, Costa DM, Oliveira TG, et al. Prevalência de Sifilis e HIV utilizando testes rápidos em parturientes atendidas nas maternidades públicas de Vitória, Estado do Espírito Santo. Rev Soc Bras Med Trop. 42(4):386-91.

[30] Saloojee, H., Velaphi, S., Goga, Y., Afadapa, N., Steen, R, Lincetto, O. (2009). The prevention and management of congenital syphilis: an overview and recommendations. Bull World Health Organ. 82:424-430.

[31] Towards universal access: scaling up priority HIV/AIDS interventions in health sector. Progress report.

2009. (http://www.who.int/hivtopics/universalaccess/en/inde .html.

[32] Chen, S. M., van den Hoek, A., Shao, C. G. et al (2002). Prevalence of and risk indicators for STIs among women seeking induced abortions in two urban family planning clinics in Shandong Province, People's Republic of China. Sex Transm Infect. 78: e3

[33] Rose, S., Lawton, B., Brown, S., Goodyear-Smith, F., Arroll, B.N.Z. (2005). Med J. 118(1211), U1348

[34] Zhou, H., Xiang-Sheng, C., Fu-Chang, H., Peng, P., Fan, Y., Yu-Mao, C., Yue-Ping, Y., Rosanna W. P., and David M. (2007). Risk factors for syphilis infection among pregnant women: results of a case-control study in Shenzhen, China. Sex Transm Infect, 83(6), 476-480. 